\title{
Comparison of Atmospheric Vertical Motion over China in ERA-Interim, JRA-55, and NCEP/NCAR Reanalysis Datasets
}

\author{
Jiayu $\mathrm{Xu}^{1,2} \cdot$ Rongxiang $\operatorname{Tian}^{1}\left(\mathbb{D} \cdot\right.$ Song Feng $^{3}$ \\ Received: 11 May 2020 / Revised: 23 December 2020 / Accepted: 6 January 2021 / Published online: 19 February 2021 \\ (C) The Author(s) 2021
}

\begin{abstract}
Vertical motion is an important feature of the atmosphere, being closely linked to clouds and precipitation. Here, we present a comparison of the vertical velocity of air over China, with particular focus on the Tibetan Plateau, during the period 1981-2010 using three reanalysis datasets: ERA-Interim, JRA-55 and NCEP/NCAR. Analysis methods including empirical orthogonal functions analysis and correlation analysis were used to examine consistency between the datasets and their suitability in research and application in China. Our results show that the vertical velocity fields from ERA-Interim and JRA-55 are more consistent than they are with those from NCEP/NCAR. The atmospheric vertical velocity fields from NCEP/NCAR lack details compared with those obtained from ERA-Interim and JRA-55, and part of values for the upper troposphere over the ocean south of $15^{\circ} \mathrm{N}$ are contrary to the other datasets and the climatic reality. Therefore, use of ERA-Interim or JRA-55 may be preferable over NCEP/NCAR. The intensity of atmospheric vertical motion in the lower troposphere in JRA-55 is significantly higher than in ERA-Interim and NCEP/NCAR. In summer, the JRA-55 data are closest to the observed wind fields and the data stability best for the Tibetan Plateau region. Our results provide guidance for better application of reanalysis data and more accurate climate prediction for this region.
\end{abstract}

Keywords Vertical motion of air $\cdot$ Reanalysis data $\cdot$ ERA-interim $\cdot$ JRA-55 $\cdot$ NCEP/NCAR $\cdot$ China

\section{Introduction}

The vertical motion of the atmosphere is a requirement for the occurrence of most weather phenomena such as clouds and rain, and an important component of large-scale atmospheric circulation and energy transport. China, located to the west of the Pacific Ocean and east of Eurasia, has a special geographical location and complex topography. In particular, the "hollow heating" of high-thermal conversion efficiency on the Tibetan Plateau means that atmospheric vertical motion over

Responsible Editor: Dr. Jung Choi.

Rongxiang Tian

trx@zju.edu.cn

1 School of Earth Sciences, Zhejiang University, 38 Zheda Road, Hangzhou 310027, China

2 Department of Atmospheric and Oceanic Sciences, School of Physics, Peking University, Beijing 100871, China

3 Department of Geosciences, University of Arkansas, Fayetteville, AR, USA
China differs from that over the other part of the world, helping to form China's unique meteorological and climate characteristics (Wang et al. 2013). Therefore, the accuracy of atmospheric vertical velocity data is of fundamental importance for studies of the weather and climate in China.

The vertical velocity of the atmosphere is not routinely observed by automatic weather stations and therefore needs to be derived by calculation and estimation. In the 1950s, the vertical velocity was mainly obtained by hand calculation and hand-painted weather maps, using algorithms such as the boundary condition method and individual variation method (Gu 1954). After the 1950s, there was development of more accurate and rapid numerical simulation and data assimilation systems that soon replaced subjective estimates (Dunn 1991). Site data can also be interpolated to a grid, which greatly improves the continuity of data in time and space.

Meteorological reanalysis datasets are products of data assimilation systems. Reanalysis datasets such as the NCEP/ NCAR Reanalysis I and NCEP/DOE Reanalysis II jointly issued by the National Centers for Environmental Predication (NCEP) and the National Center for Atmospheric Research (NCAR), ERA-40 and ERA-Interim 
produced by the European Centre for Medium-Range Weather Forecasts (ECMWF), JRA-25 and JRA-55 from the Japan Meteorological Agency (JMA), and the Modern-Era Retrospective analysis for Research and Applications (MERRA) dataset released by National Aeronautics and Space Administration (NASA), are of high credibility, good quality, and are widely in use. However, due to the differences in computing methods, assimilation schemes, data sources, and deviation correction methods, the results of various reanalysis datasets vary significantly from one to another (Tian et al. 2017).

Previous research studies have compared different reanalysis datasets with regard to their representation of elements such as temperature, precipitation, geopotential height, circulation, and the heat source distribution at different space-time scales. Zhao and Fu (2009) found that ERA-40 and JRA-25 better describe surface air temperatures in China than do NCEP/NCAR and NCEP/DOE. To be more specific, JRA25 has higher reliability with regard to the mean value, interannual variation and variability, whereas ERA-40 better captures the long-term climate change trends. For potential height and temperature in the upper troposphere in North China, NCEP/NCAR is better than ERA-40 (Huang 2006). Both NCEP/NCAR and NCEP/DOE generally overestimate precipitation in China when compared with station observations but in contrast, precipitation is underestimated in the equatorial Pacific Ocean (Wu and Xie 2003; Zhao et al. 2004). The accuracy of reanalysis data in the Tibetan Plateau is also a research focus. Numerous studies have shown clear differences in this region among different reanalysis datasets. For example, surface temperatures in JRA-25 are generally overestimated (Li et al. 2012), whereas they are underestimated in NCEP/DOE, the latter resulting in systematically lower surface long-wave radiation and atmospheric counter radiation (Wei and Li 2003). ERA-Interim's description of surface temperature in the Tibetan Plateau is relatively better (He et al. 2013). ERA-Interim is also better than NCEP/ NCAR and NCEP/DOE in describing the plateau's heat source (Tian et al. 2017). It has been shown that MERRA is superior to NCEP/NCAR in its representation of the South Asian High (Wang 2011). As for the applicability of geopotential height over the Tibetan Plateau, NCEP/NCAR and ERA-Interim are the superior datasets (Hu et al. 2015).

Although much research has been done in this area, there has been no comparative analysis of reanalysis data for atmospheric vertical motion. Moreover, the reanalysis datasets used, such as ERA-40 and JRA-25, are now outdated. The major forecasting centers constantly update and improve their data assimilation systems and therefore release new and more complete reanalysis datasets, such as ERA-Interim and JRA55. Therefore, it is necessary to compare and verify the distribution and applicability of atmospheric vertical motion over China, especially over the Tibetan
Plateau, in the updated reanalysis datasets in order to provide a more practical and reliable reference for dataset selection in future research.

\section{Data and Methods}

\subsection{Reanalysis Datasets}

Atmospheric vertical motion, $\omega(\mathrm{Pa} / \mathrm{s})$, from three reanalysis datasets (ERA-Interim, JRA-55 and NCEP/NCAR) is used to characterize the vertical velocity of the atmosphere where $\omega>0$ means sinking and $\omega<0$ means ascending. ERA-Interim and JRA-55 are the most recent and most widely used reanalysis datasets produced by ECMWF and JMA, respectively. NCEP/NCAR was chosen over NCEP/DOE because the performance of NCEP/DOE has not been significantly improved, whereas the data assimilation system of NCEP/NCAR is currently being improved, and its application is wider than that of NCEP/ DOE (He et al. 2013; Hu et al. 2015; Tian et al. 2017; Wang et al. 2012; Zhao et al. 2004; Zhao and Fu 2009). ERA-Interim is derived from the Integrated Forecast System (IFS) whose model horizontal resolution is $0.1^{\circ}$ ( $\sim 9 \mathrm{~km})$ (ECMWF 2010). JRA-55 is one of the products of low-resolution (TL319, 55 km) version of JMA's operational data assimilation system (Kobayashi et al. 2015). NCEP/NCAR use the T62 model ( $210 \mathrm{~km})$ (Kalnay et al. 1996) whose model horizontal resolution is coarser than ERA-Interim and JRA-55.

Monthly average data of ERA-Interim and JRA-55, and daily average data of NCEP/NCAR from 1981 to 2010 were selected. Monthly averages were calculated from the daily average data of NCEP/NCAR. Thirtyyear climatic averages and seasonal averages of the air vertical velocity were calculated from the monthly averages. The winter 2010 average was calculated using monthly average data of December 2010, January and February 2011. The horizontal resolution of all three datasets is $2.5^{\circ} \times 2.5^{\circ}$. In addition to the common isobaric surfaces such as $925 \mathrm{hPa}, 700 \mathrm{hPa}, 500 \mathrm{hPa}$, $200 \mathrm{hPa}$, and $100 \mathrm{hPa}$, the $600 \mathrm{hPa}$ level with a vertical height of about $4.2 \mathrm{~km}$ is also included to represent the surface of the plateau, considering the average surface elevation of the Tibetan Plateau is about $4.5 \mathrm{~km}$ (Xun et al. 2011).

The formula for calculating the vertical velocity $\omega$ of air in the spherical coordinate system $(\lambda, \theta, \eta)$ in ERA-Interim is as follow (ECMWF 2010):

$\omega=-\int_{0}^{\eta} \nabla \cdot\left(v_{H} \frac{\partial p}{\partial \eta}\right) d \eta+v_{H} \cdot \nabla p$ 
where $\mathrm{v}_{\mathrm{H}}=(\mathrm{u}, \mathrm{v})$ is the horizontal wind. The vertical velocity expressed in $\eta$-corrdinate is calculated from the following formula:

$\dot{\eta} \frac{\partial p}{\partial \eta}=-\frac{\partial p}{\partial t}-\int_{0}^{\eta} \nabla \cdot\left(v_{H} \frac{\partial p}{\partial \eta}\right) d \eta$

The NCEP/NCAR model uses the $\sigma$ vertical coordinate, and the diagnostic equations for the vertical velocity expressed in $\sigma$-corrdinate are as follows (Bourke 1974; $\mathrm{Hu}$ 2006):

$$
\begin{gathered}
\dot{\sigma}=\left\{(1-\sigma) \bar{D}-\bar{D}^{\sigma}\right\}+\left\{(1-\sigma) \bar{V}-\bar{V}^{\sigma}\right\} \cdot \nabla q \\
\overline{()}=\int_{\sigma=1}^{0}() \partial \sigma ; \overline{(~)}^{\sigma}=\int_{\sigma=1}^{\sigma}() \partial \sigma
\end{gathered}
$$

The vertical velocity $\omega$ in the $p$ vertical coordinate can be converted using the relational expression of $\sigma$ and $p$.

\subsection{Principal Component Analysis and Correlation Analysis}

In the research, we analyze and compare the datasets by season. We use the average vertical velocity of March, April and May representing spring, the average of June, July and August representing summer, the average of September, October and November representing autumn, the average of December, January and February of next year representing winter.

The method of empirical orthogonal functions (EOFs, also known as principal component analysis) is used to extract the main characteristics of the air vertical velocity anomaly at $500 \mathrm{hPa}$ for both summer and winter in the research. EOFs are derived from covariance matrices in this study. Considering an observational variable at multiple positions in space and at multiple times, it can be arranged in a $\boldsymbol{N} \times \boldsymbol{M}$ matrix $\mathbf{F}$. The time-mean is then removed from of the $\boldsymbol{M}$ time series to form the anomaly matrix A whose columns have zero-mean:

$\mathbf{A}=\left(\begin{array}{cccc}a_{1,1} & a_{1,2} & & \\ a_{2,1} & a_{2,2} & & a_{1, M} \\ & \vdots & & a_{2, M} \\ a_{N, 1} & a_{N, 2} & \cdots & a_{N, M}\end{array}\right)$

Then the covariance matrix $\mathbf{R}=\mathbf{A}^{T} \mathbf{A}$ is computed to solve the eigenvalue problem:

$\mathbf{R C}=\mathbf{C} \Lambda$

where the leading diagonal of $\Lambda$ are the eigenvalue (EOF variances) and the columns of $\mathbf{C}$ are the eigenvectors (EOFs) (Dawson, A., http://ajdawson.github.io/eof2/eofs.html\#id5). The first principal component (PC1) of three reanalysis datasets are compared to try to distinguish the best one from them.

To better make out the relationship between three reanalysis datasets, we use correlation analysis in the research. The computation formula of correlation coefficient is as follow:

$\mathrm{r}(\mathrm{x}, \mathrm{y})=\frac{\sum(x-\bar{x})(y-\bar{y})}{\sqrt{\sum(x-\bar{x})^{2} \sum(y-\bar{y})^{2}}}$

where $\bar{x}$ and $\bar{y}$ are the average of $\mathrm{x}$ and $\mathrm{y}$ respectively. We test the significance of the correlation coefficients at a $95 \%$ confidence level by Student's $t$ test.

\section{Results}

\subsection{Comparison of Climatic Averages}

Figure 1 shows the distribution of the climatic average of air vertical velocity at $925 \mathrm{hPa}, 600 \mathrm{hPa}$, and $100 \mathrm{hPa}$. The general characteristics of the distributions are similar among the three datasets. For example, at each isobaric surface, the vertical velocity of air is positive from North China to Inner Mongolia, northern Xinjiang, and the subtropical high in the Northwest Pacific, indicating descending motion in the atmosphere. Over South China, parts of south-central Xinjiang, and the southern foothills of the Himalayas, as well as over the western Pacific warm pool and the Kuroshio region, the vertical velocity of air is negative from the surface to $200 \mathrm{hPa}$, indicating the consistent ascending motion of the atmosphere. These features correspond well with the climate characteristics of each region. In the middle and lower troposphere, the three datasets show that there is a significant alternation of ascending and descending motion stretching from eastern Japan to Mongolia. This phenomenon weakens with increasing geopotential height. It can be inferred that there are multiple small-scale zonal circulations over these regions.

There are, however, notable differences in the distributions among the three datasets. Although they share the same horizontal resolution, the distributions obtained from ERAInterim and JRA-55 are more similar than they are to NCEP/ NCAR (Fig. 1). Their ascending and descending centers are more detailed than those in NCEP/NCAR, whose images are smoother. One of the likely reasons is that the horizontal resolutions of the models where reanalysis data derived from are different. The model of NCEP/NCAR using the T62 resolution equivalent to about $210 \mathrm{~km}$ which is much coarser than the resolution of the model of ERA-Interim and JRA-55.

The vertical motion intensity in the middle and lower troposphere is stronger in JRA-55 than in ERA-Interim and NCEP/NCAR, especially the descending motion at $925 \mathrm{hPa}$ 

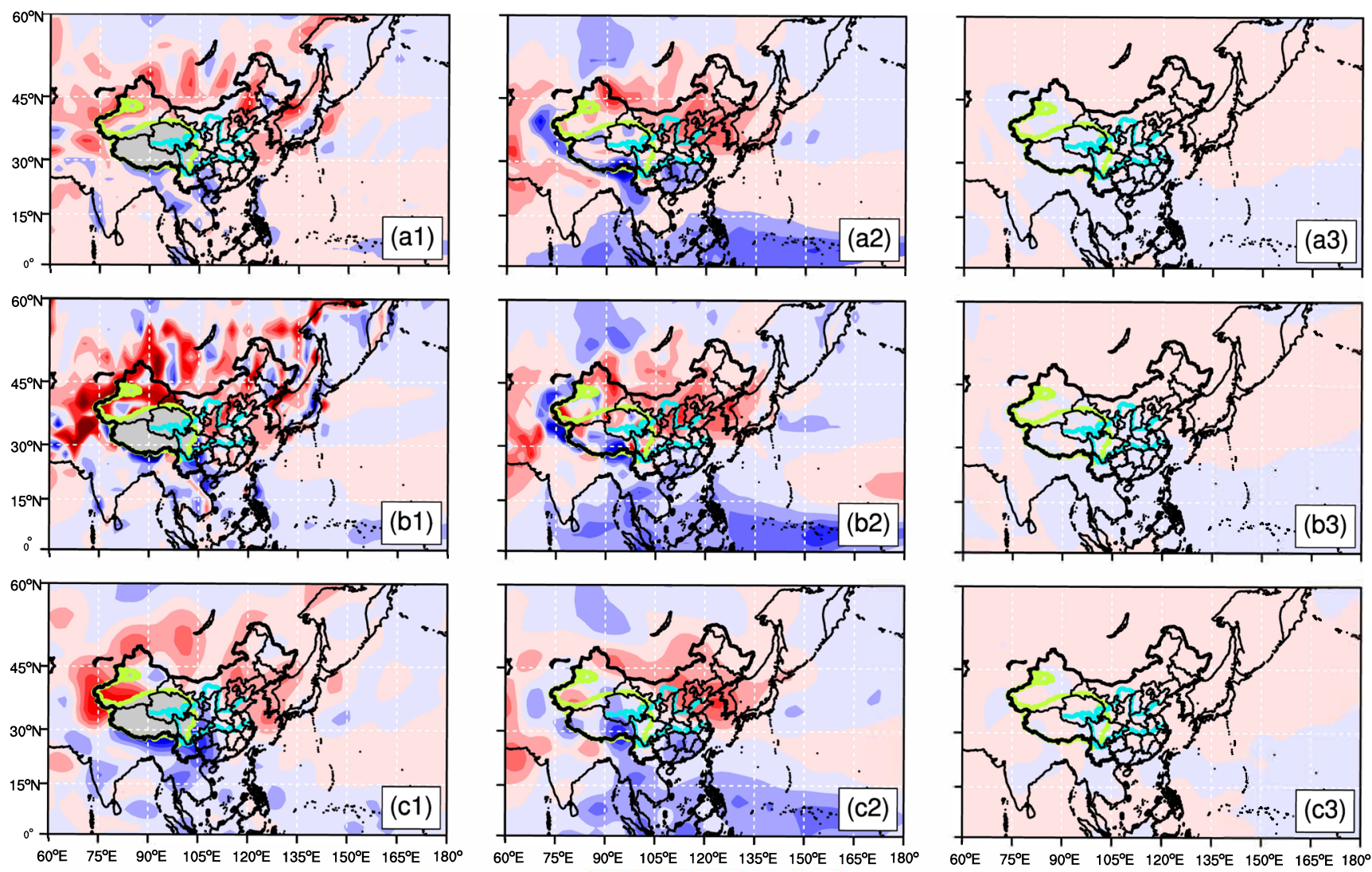

\section{$\begin{array}{llll}-0.16 & -0.12 & -0.08 & -0.04\end{array}$}

Fig. 1 The distribution of climatic average vertical velocity $(\mathrm{Pa} / \mathrm{s})$ over China at $925 \mathrm{hPa}$ (a1, b1, c1), $600 \mathrm{hPa}(\mathrm{a} 2, \mathrm{~b} 2, \mathrm{c} 2)$, and $100 \mathrm{hPa}$ (a3, b3,

c3) from 1981 to 2010 in ERA-Interim (a1, a2, a3), JRA-55 (b1, b2, b3)

and NCEP/NCAR (c1, c2, c3). The green line is the profile of Tibetan Plateau, and the cyan lines mark the Yangtze River and Yellow River. Areas shaded gray have no data

over northwestern Xinjiang and at $600 \mathrm{hPa}$ near the Northwest Pacific subtropical high (Fig. 1b). The main difference in the lower troposphere between the three datasets is that Shanxi Province is under the control of descending motion in ERAInterim and JRA-55, while it is under the control of ascending motion in NCEP/NCAR. In addition, the vertical motion in the lower troposphere from southern Xinjiang to Gansu Province is also different that ERA-Interim shows ascending motion, JRA-55 shows descending in the east and ascending in the west, while NCEP/NCAR shows descending in the west and ascending in the east. Consistency among the three products is good in the middle troposphere, except for the Tibetan Plateau. In the central plateau, ERA-Interim has a descending center, whereas there is rising vertical motion at this location in JRA-55 and NCEP/NCAR. JRA-55 has obvious descending motion in the northwest corner, southeast corner and north of the plateau, while ascending motion dominates the region in NCEP/NCAR. The major difference in the upper troposphere at $100 \mathrm{hPa}$ is that NCEP/NCAR shows sinking over the South China Sea and the Bay of Bengal, which is contrary to ERA-Interim and JRA-55 and does not reflect the profound features of the Pacific warm pool.
In summary, JRA-55 and ERA-Interim have strong similarities in regions other than the Tibetan Plateau, where the differences among the three datasets are relatively significant.

\subsection{Comparison of Seasonal Averages}

\subsubsection{Spring and Autumn}

The average vertical velocity distributions in spring (Fig. 2) and autumn (Fig. 3) are similar to the distributions of the climatic averages, especially the positions of the ascending and sinking centers, as well as the alternating small-scale circulations in the lower troposphere over eastern Japan and Mongolia. However, there are notable differences.

In spring, the descending center in the vicinity of the Northwest Pacific subtropical high (Fig. 2a2-c2) is larger and more intense than this feature in the climatic average (Fig. 1a2-c2). In autumn, the average sinking intensity in ERA-Interim falls between that in spring and the climate average for this area. In JRA-55 the sinking is weaker in autumn than that in spring and the climate average, and in NCEP/ NCAR the sinking is similar to the spring average (Fig. 3a2- 

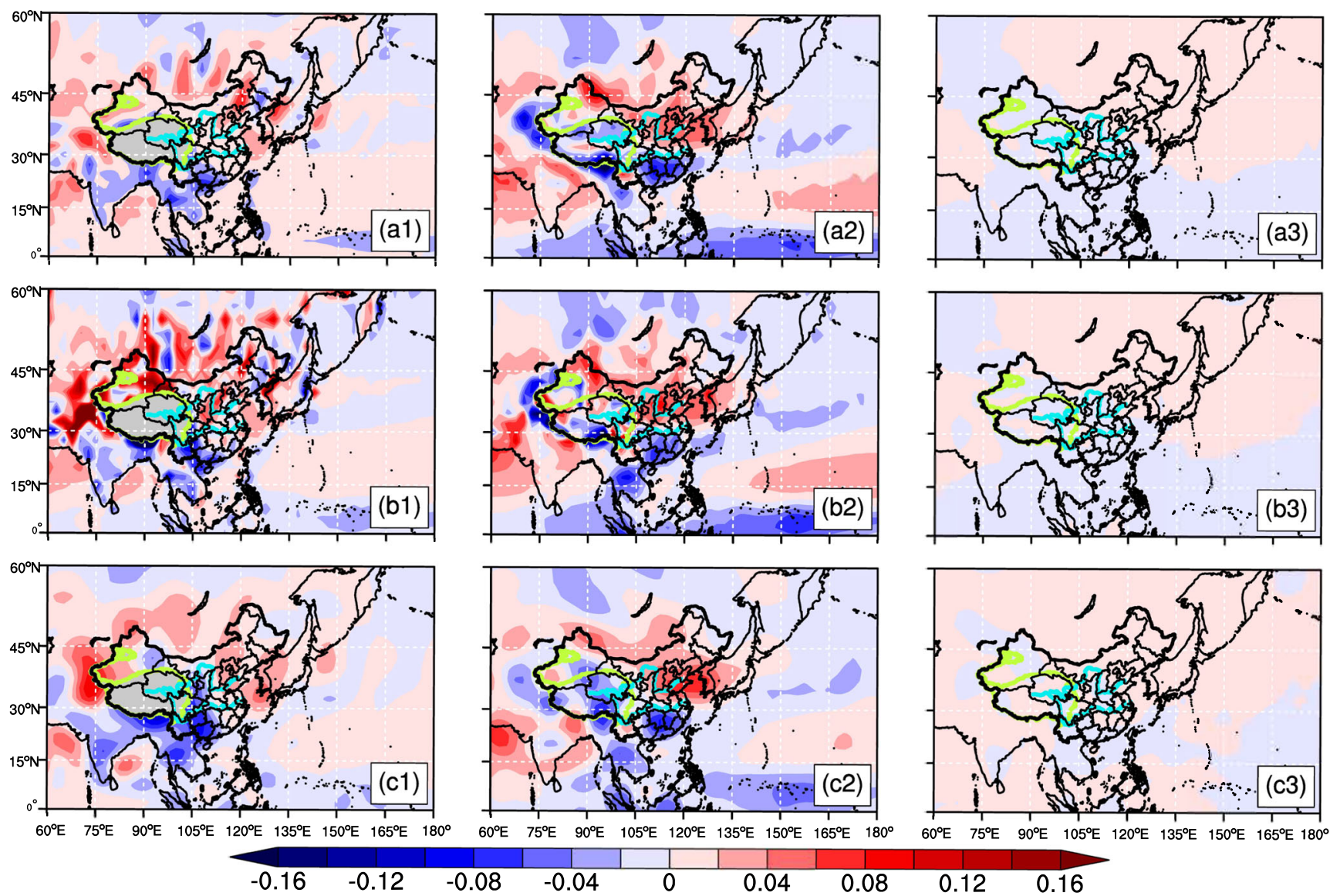

$-0.04$

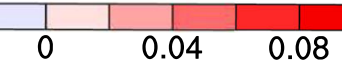

0.12

0.16

Fig. 2 As in Fig. 1 but for spring (March-May)

c2). In addition, the average ascending intensity in JRA-55 is clearly greater than that in ERA-Interim and NCEP/NCAR in the lower troposphere over southern Tibet in the corresponding season. At $600 \mathrm{hPa}$, the ascending motion is strongest in ERA-Interim. At all isobaric surfaces, the descending motion over Northeast China is stronger in autumn than in spring.

\subsubsection{Summer}

The distribution characteristics of vertical velocity are more significant in summer and winter than the other seasons. The three reanalysis datasets show good consistency at all isobaric surfaces in summer (Fig. 4). Ascending motion prevails both over the Pacific Ocean, over all parts of China except northern Xinjiang, Inner Mongolia and Shaanxi, and is strongest over the Pacific warm pool south of $15^{\circ} \mathrm{N}$, the southern foothills of the Himalayas, and the Bay of Bengal.

In summer, the spatial distribution of air vertical motion at $925 \mathrm{hPa}$ is less intense and patchier than the distribution at $600 \mathrm{hPa}$. A relatively obvious difference is that ERA-Interim and JRA- 55 have a sinking area extending from the west to the center over Xinjiang, whereas this feature is not apparent in NCEP/NCAR (Fig. 4a1-c1). In the middle troposphere, there is a sinking center extending north to southeast over Xinjiang; the sinking velocity is largest in JRA-55 and smallest in NCEP/NCAR. In addition, JRA-55 has a larger and stronger descending center over western Inner Mongolia-Shanxi compared with ERA-Interim and NCEP/NCAR. In the upper troposphere, the three datasets show prevailing ascending motion in the vast area east of $75^{\circ} \mathrm{E}$, but in NCEP/NCAR there is weak sinking over the Pacific warm pool, which is not consistent with the other datasets and the climatic reality.

Next, we compared PC1 of EOF analysis for air vertical velocity anomaly at $500 \mathrm{hPa}$ in summer. The explained variance of $\mathrm{PC} 1$ of three datasets is only around $10 \%$ (Fig. 5a2c2), indicating that the spatial distribution pattern of the original anomaly field is complicated. The anomaly distribution patterns of ERA-Interim and JRA-55 are similar while in NCEP/NCAR the intensity is weaker. For example, in ERAInterim and JRA-55 there is a positive anomaly center over the east coast of the Bay of Bengal and over the Pacific Ocean. The positive and negative values in these areas are the same in NCEP/NCAR but there is no obvious center, indicating that the vertical velocity is relatively smaller. From the PC1 time series, it can be seen that the trends in ERA-Interim and JRA55 are almost completely coincident, whereas the NCEP/ NCAR trend is quite different, especially during the periods of 1980-1985, 1990-1995, 1996-1999 and 2002-2004. 

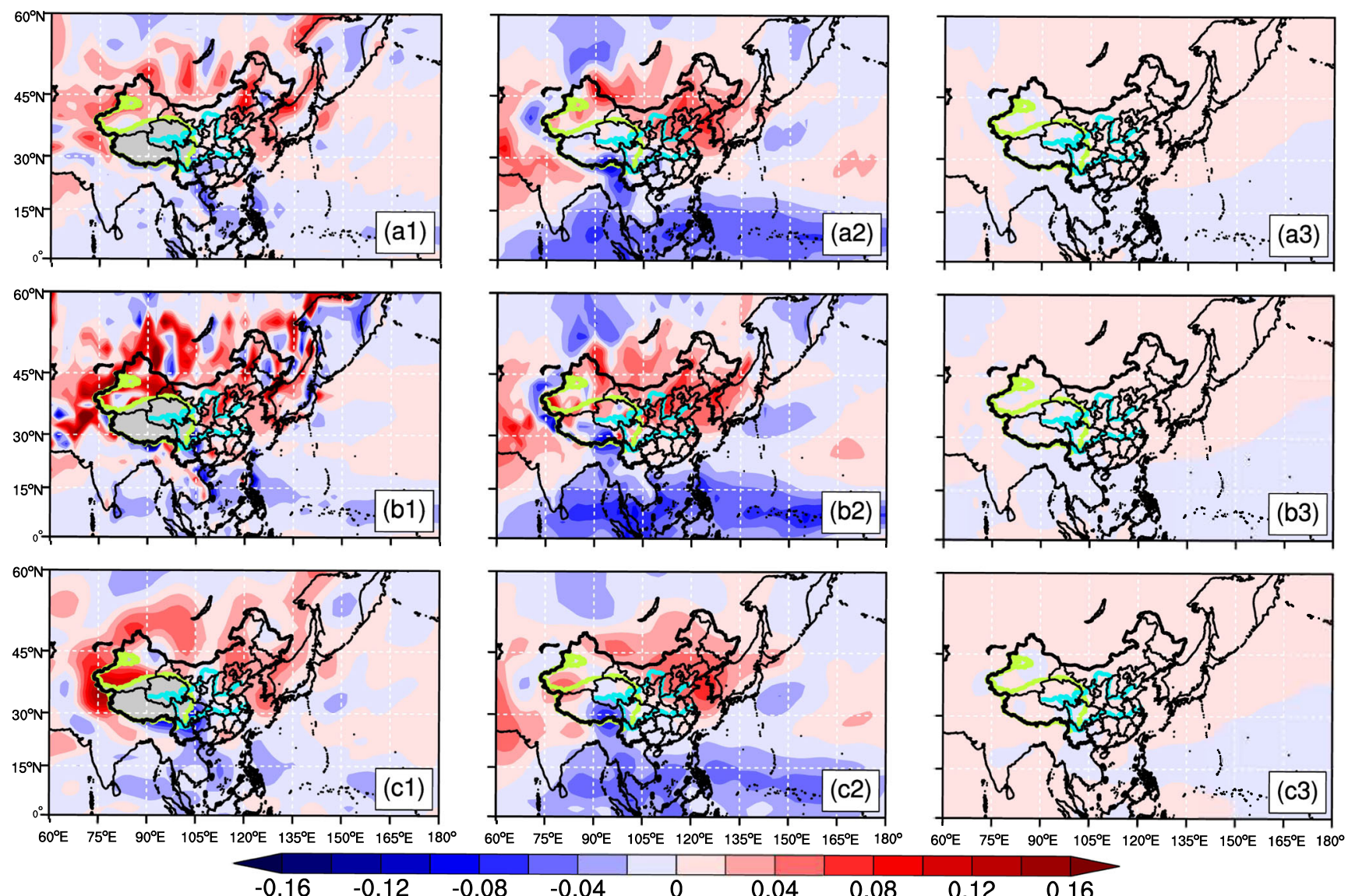

Fig. 3 As in Fig. 1 but for autumn (September-November)

\subsubsection{Winter}

The distribution of the average vertical velocity in winter is more complicated than that in summer that not all regions prevail descending motion (Fig. 6). In the middle and lower troposphere, most regions are dominated by descending motion, while ascending motion prevails over South China, the west of Yunnan, the southeastern part of the Tibetan Plateau, the Pacific warm pool and the north of the Pacific.

The most significant difference between the three reanalysis datasets is that the descending motion, especially at $925 \mathrm{hPa}$, is stronger in JRA-55 than it is in ERAInterim and NCEP/NCAR. In ERA-Interim and NCEP/NCAR, the strength of the descending motion below the middle troposphere is more moderate and similar, yet NCEP/NCAR is as detailed as that of ERA-Interim. At $500 \mathrm{hPa}$, the intensity in ERA-Interim becomes similar to that in JRA-55 and the strength of NCEP/NCAR is relatively weaker. At $200 \mathrm{hPa}$ (results not shown), ERAInterim and JRA-55 both have a small region of sinking along the Himalayas, which is not evident in NCEP/NCAR. NCEP/NCAR has a belt of prominent descending motion over Hebei and Shandong that stretches to the Korean peninsula; this feature is not evident in the other datasets. At $100 \mathrm{hPa}$, the intensity of all vertical motion suddenly decreases compared with that of the lower isobaric surfaces. Similar to the previous results, there are large discrepancies in the weak ascending area in NCEP/NCAR, ERA-Interim and JRA-55. Furthermore, NCEP/NCAR has weak descending motion rather than weak ascending motion over the Bay of Bengal, the Indian Peninsula and the Indian Ocean in the west, which is contrary to the other datasets.

The PC1 of EOF for the $500 \mathrm{hPa}$ air vertical velocity in winter (Fig. 7) is different from that for summer, with larger explained variances for ERA-Interim $(17.6 \%)$ and JRA-55 (15.6\%), while the value for NCEP/NCAR is only about $9.5 \%$. This means the PC1 of ERA-Interim and JRA-55 contain more information about original anomaly field than that of NCEP/NCAR. The spatial distributions in ERA-Interim and JRA-55 remain similar. NCEP/ NCAR has regions with a spatial pattern inverse to those from the other two datasets, with a region of positive values over the middle of the Tibetan Plateau and a region of negative values over southern central China. These results indicate that the vertical velocity reanalysis data from NCEP/NCAR is quite different from the other two datasets. 

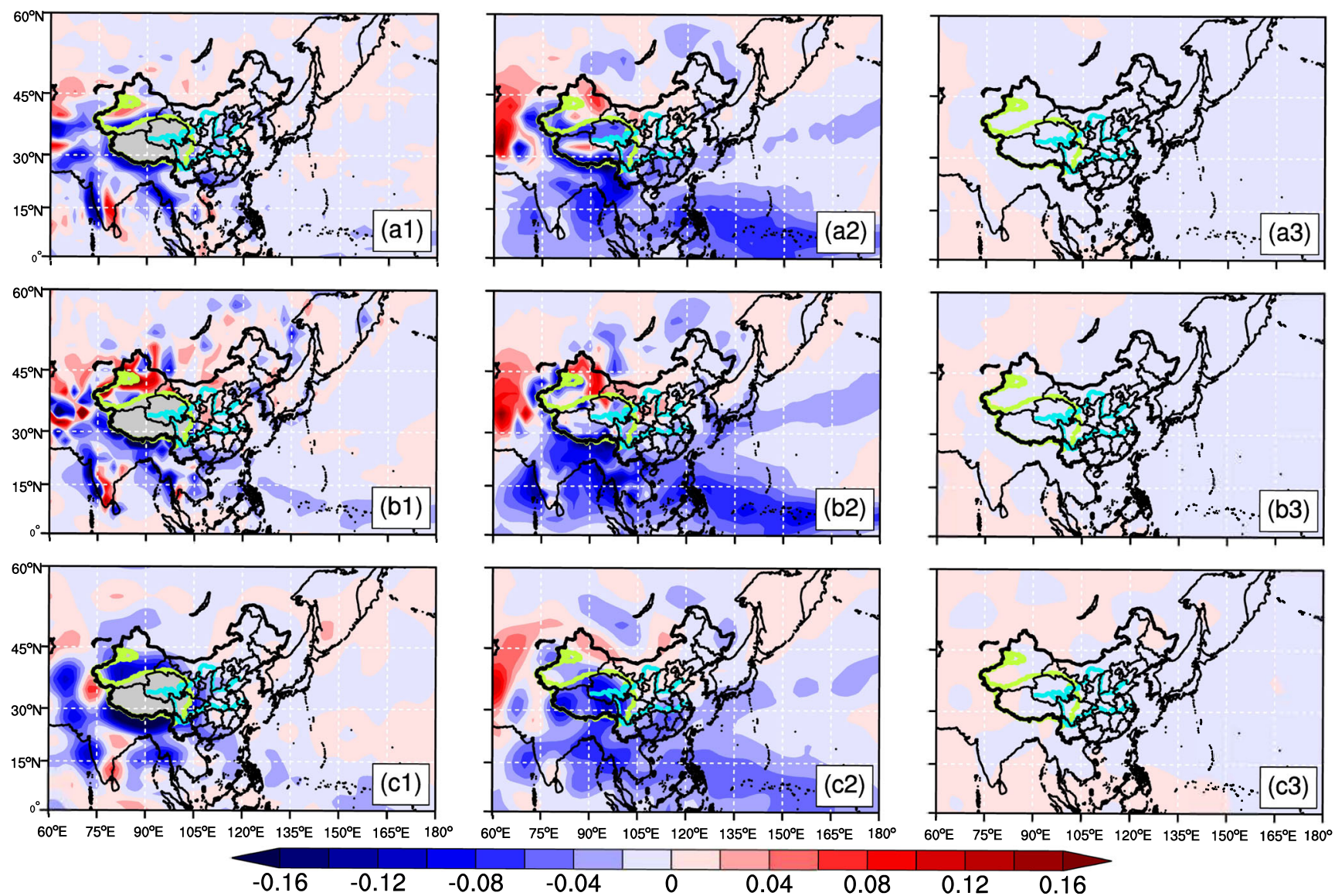

$-0.04$

Fig. 4 As in Fig. 1 but for summer (June-August)

\subsection{Comparison for the Tibetan Plateau}

The high elevation of the Tibetan Plateau has always been highlighted and emphasized in studies of atmospheric vertical motion over China. Due to the sparsity of meteorological stations in the Tibetan Plateau and the incomplete of satellite data, observational data is limited in both the spatial and temporal domains. Therefore, studies of this region often rely on reanalysis data. However, differences in both the magnitude and spatial distribution of air vertical velocity values among the various reanalysis data are often large.

\subsubsection{Summer}

In the lower layer of the atmosphere $(600 \mathrm{hPa})$ over the Tibetan Plateau in summer (Fig. 4a2-c2), ERA-Interim has two prominent sinking centers in the middle of the plateau, with stronger sinking in the western center and slightly weaker sinking in the eastern center. JRA-55 also has a small region of sinking in the northwest and southeast of the plateau, but these are less pronounced. The intense sinking of JRA-55 is located over the northeastern plateau. NCEP/NCAR doesn't show obvious descending motion over the plateau. The distribution of the vertical velocity over the plateau in ERA-Interim and JRA-55 is similar to the results shown by Yeh et al. (1979) using the wind data in Northern Hemisphere High Altitude Climate Atlas (1972), as well as the results from $\mathrm{Xu}$ and Zhang (1983) using the wind data in Plateau Climate Atlas (Lanzhou Institute of Plateau Atmospheric Physics 1979) and High-altitude wind data in China (China Meteorological Administration 1972) that ascending motion is dominant over the center of plateau from east to west, and descending motion is dominant over the northern and southern part of the plateau, while the distribution of NCEP/NCAR is slightly different from them. Yeh et al. (1979) and Xu and Zhang (1983) derived the vertical velocity over Tibetan Plateau and its vicinity in July in 1960s at six vertical layers from the in-situ observational horizontal wind speed every 5 or 2.5 latitude and longitude degrees respectively and the descending motion area in the north of the plateau of the latter extends more southwards. Yeh et al. (1979) points out that the descending motion over the southern part is a feature of only the middleupper troposphere and the descending over the northern part is a feature of only the middle-lower troposphere. These descending motions at different layers have a tendency to get through near $95^{\circ} \mathrm{E}$. They also found that there is a small fluctuation in the plateau monsoon circulation, which is located over the east of the plateau. From these points of view, the 

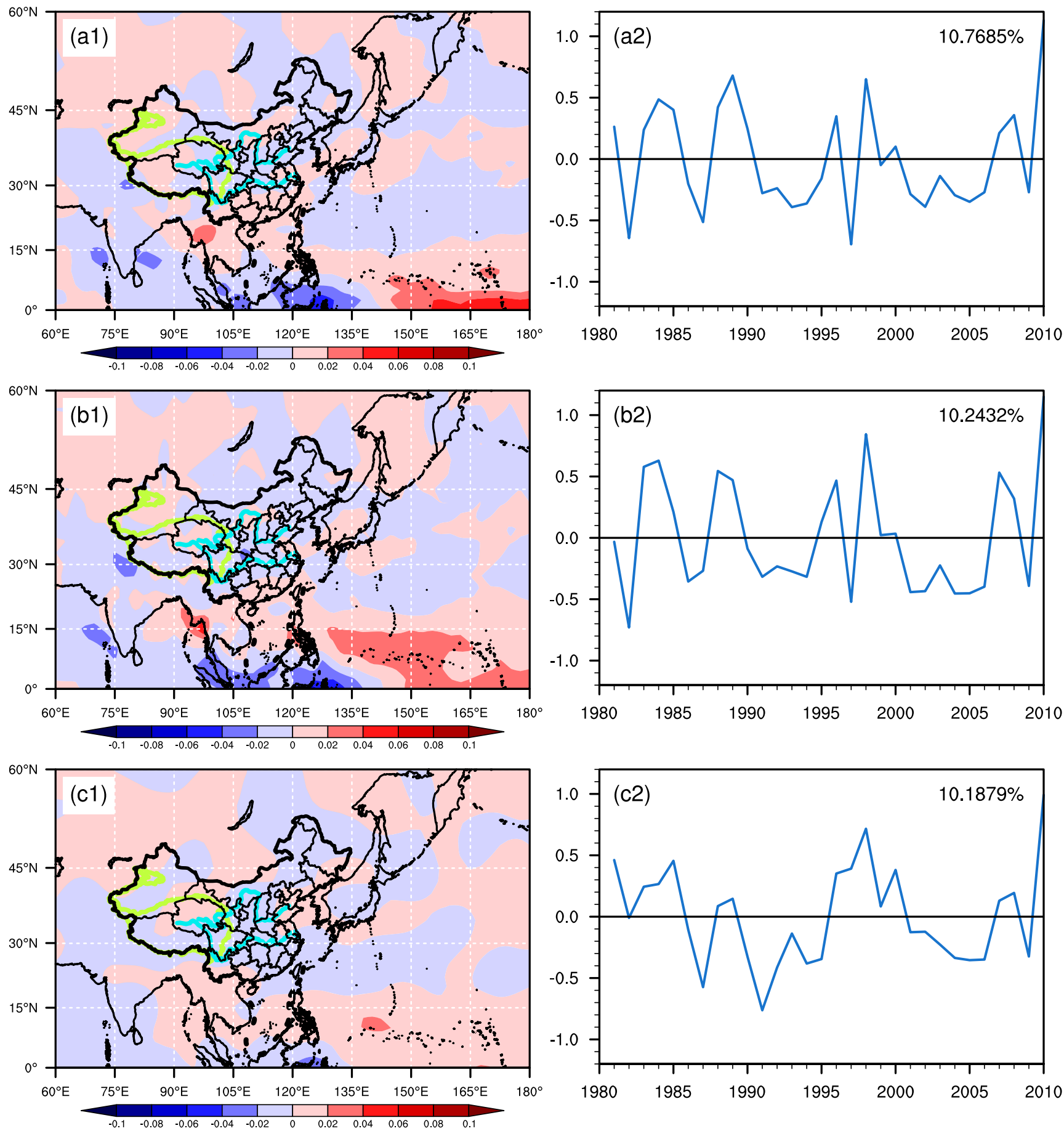

Fig. 5 (Left panels) Spatial distribution of EOF and (right panels) time series of the first principal component of the summer vertical velocity anomaly for 1981-2010 based on a ERA-Interim, b JRA-55, and c

vertical motion reanalysis data of JRA-55 matches the results of Yeh et al. (1979) and Xu and Zhang (1983) based on wind measurements better than ERA-Interim.

The interannual variation of the summer averaged vertical velocity over the Tibetan Plateau and its vicinity (25$45^{\circ} \mathrm{N}, 75-105^{\circ} \mathrm{E}$ ) at $600 \mathrm{hPa}, 500 \mathrm{hPa}$ and $100 \mathrm{hPa}$ is shown in Fig. 8. For each isobaric surface, the interannual
NCEP/ NCAR. The percentage in the top right of the time series panels indicates the explained variance of PC1

variation in the three datasets is generally consistent, especially at $100 \mathrm{hPa}$ where the features are well correlated. At this height, the correlation coefficient between the different pairs of datasets is as high as 0.98 (Table 1). However, Fig. 8 and Table 1 both indicate that the lower the isobaric surfaces, the smaller the correlation coefficients. At $100 \mathrm{hPa}$ (Fig. 8a, the average vertical velocity in ERA- 

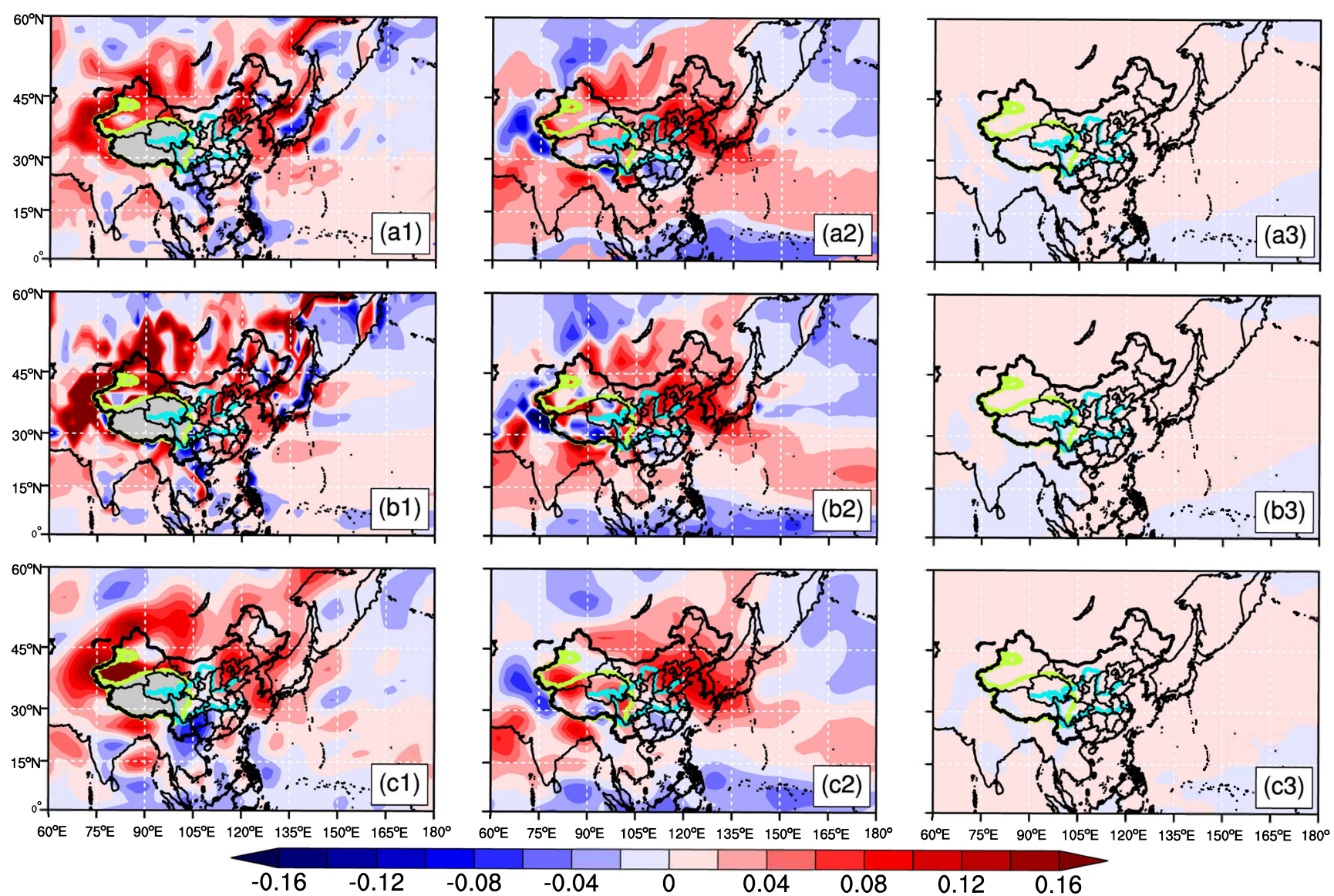

Fig. 6 As in Fig. 4 but for winter

Interim and JRA-55 is very close, in the range $-0.0070-$ $-0.0020 \mathrm{~Pa} / \mathrm{s}$, whereas the values are lower in NCEP/ NCAR indicating that the ascending motion is not as strong as in the other two datasets. In 1981, 1989 and 2009 , the average summer vertical velocity in NCEP/ NCAR over the Tibetan Plateau even becomes positive indicating weak sinking motion. This result is unique to NCEP/NCAR and also contrary to previous research results, which may indicate the limited applicability of this dataset for this region.

At $500 \mathrm{hPa}$ (Fig. 8b, the average vertical velocities in ERAInterim and NCEP/NCAR are closer before 1988, lying in the range $-0.030--0.015 \mathrm{~Pa} / \mathrm{s}$, and their absolute values are smaller than those in JRA-55 $(-0.032--0.024 \mathrm{~Pa} / \mathrm{s})$. After 1988, the vertical velocities of ERA-Interim and JRA-55 gradually converge and track each other, while the magnitude in NCEP/NCAR remains stable. After 2005, there is good agreement between the datasets.

At $600 \mathrm{hPa}$ (Fig. 8c, the absolute value of ERA-Interim's vertical velocity is the smallest before 1995, and NCEP/ NCAR is the largest. After 1995, the time series greatly diverge. The correlation coefficients between the different dataset pairings are extremely small, with a negative correlation coefficient between ERA-Interim and NCEP/NCAR. The correlation coefficient between ERA-Interim and JRA-55 remains relatively high $(0.7)$.

In summary, for the Tibetan Plateau region during the period 1981-2010, the stability of the vertical motion reanalysis data of JRA-55 is the best of the three datasets, but its intensity at $100 \mathrm{hPa}$ and $500 \mathrm{hPa}$ is slightly larger than the other datasets. After 2000, the ERA-Interim and JRA-55 time series converge and have similar trends. At the lowest level of $600 \mathrm{hPa}$, the JRA55 values are between those of ERA-Interim and NCEP/NCAR, and are closest to the results of Yeh et al. (1979). Therefore, although the ERA-Interim and JRA-55 results are similar, JRA-55 may be preferable for research into atmospheric vertical motion over the Tibetan Plateau in summer.

\subsubsection{Winter}

In winter, atmospheric vertical motion over the Tibetan Plateau is dominated by descending motion, except for an ascending center in the middle troposphere $(600-500 \mathrm{hPa})$ over southern Tibet. However, sinking motion is apparent in the upper troposphere $(200 \mathrm{hPa})$ over this region. There is little difference in these results among the three reanalysis datasets. 

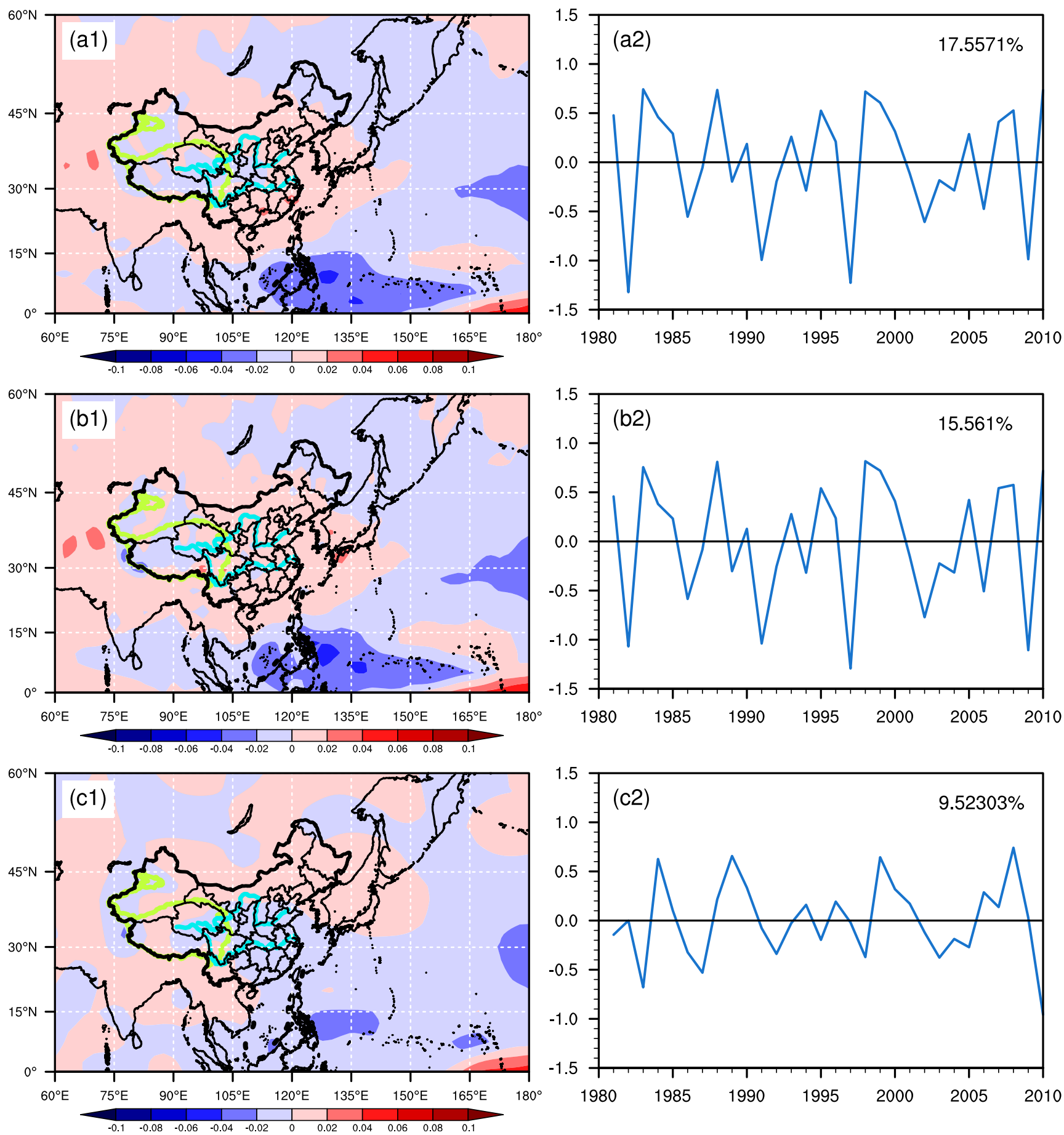

Fig. 7 As in Fig. 5 but for winter

The interannual variation trend of three reanalysis datasets for the Tibetan Plateau in winter is quite different from that in summer. Whether at $100 \mathrm{hPa}, 500 \mathrm{hPa}$ or $600 \mathrm{hPa}$, the average vertical velocity in three reanalysis datasets is close (Fig. 9), as verified by the relatively larger correlation coefficients (Table 2). However, the vertical velocity magnitudes clearly vary among the datasets. As in summer, at $100 \mathrm{hPa}$ the average vertical velocity values of the three datasets are consistent, and the correlation coefficient is as high as 0.98. During 1981-2010, the winter average vertical velocity was nearly always positive in NCEP/NCAR, whereas in approximately half of the years the average values were negative in ERAInterim and JRA-55 which means the upper level of the atmosphere is dominated by ascending motion in some years. Yang et al. (1979) pointed out that there is a certain rationality for the ascending motion at $100 \mathrm{hPa}$ over the Tibetan Plateau, 
Table 1 Correlation coefficient of the summer average air vertical velocity over the Tibetan Plateau from 1981 to 2010 , at three different geopotential heights, between each pairing of the three datasets

\begin{tabular}{llcl}
\hline & r_EJ & rab & r_JN ${ }^{\mathrm{a}, \mathrm{b}}$ \\
\hline $600 \mathrm{hPa}$ & $0.70^{*}$ & -0.12 & 0.24 \\
$500 \mathrm{hPa}$ & $0.66^{*}$ & 0.24 & $0.41^{*}$ \\
$100 \mathrm{hPa}$ & $0.98^{*}$ & $0.85^{*}$ & $0.86^{*}$ \\
\hline
\end{tabular}

${ }^{a}$ r_EJ is the correlation coefficient between ERA-Interim and JRA-55; r_EN is the correlation coefficient between ERA-Interim and NCEP/NCAR; and $r$ JN is the correlation coefficient between JRA-55 and NCEP/NCAR

${ }^{\mathrm{b}}$ All of the correlation coefficient has been tested the significance at a $95 \%$ confidence level. The right superscript ' $*$ ' indicates that the correlation coefficient is significant at $95 \%$ confidence level. Same as the correlation coefficient in Table 2
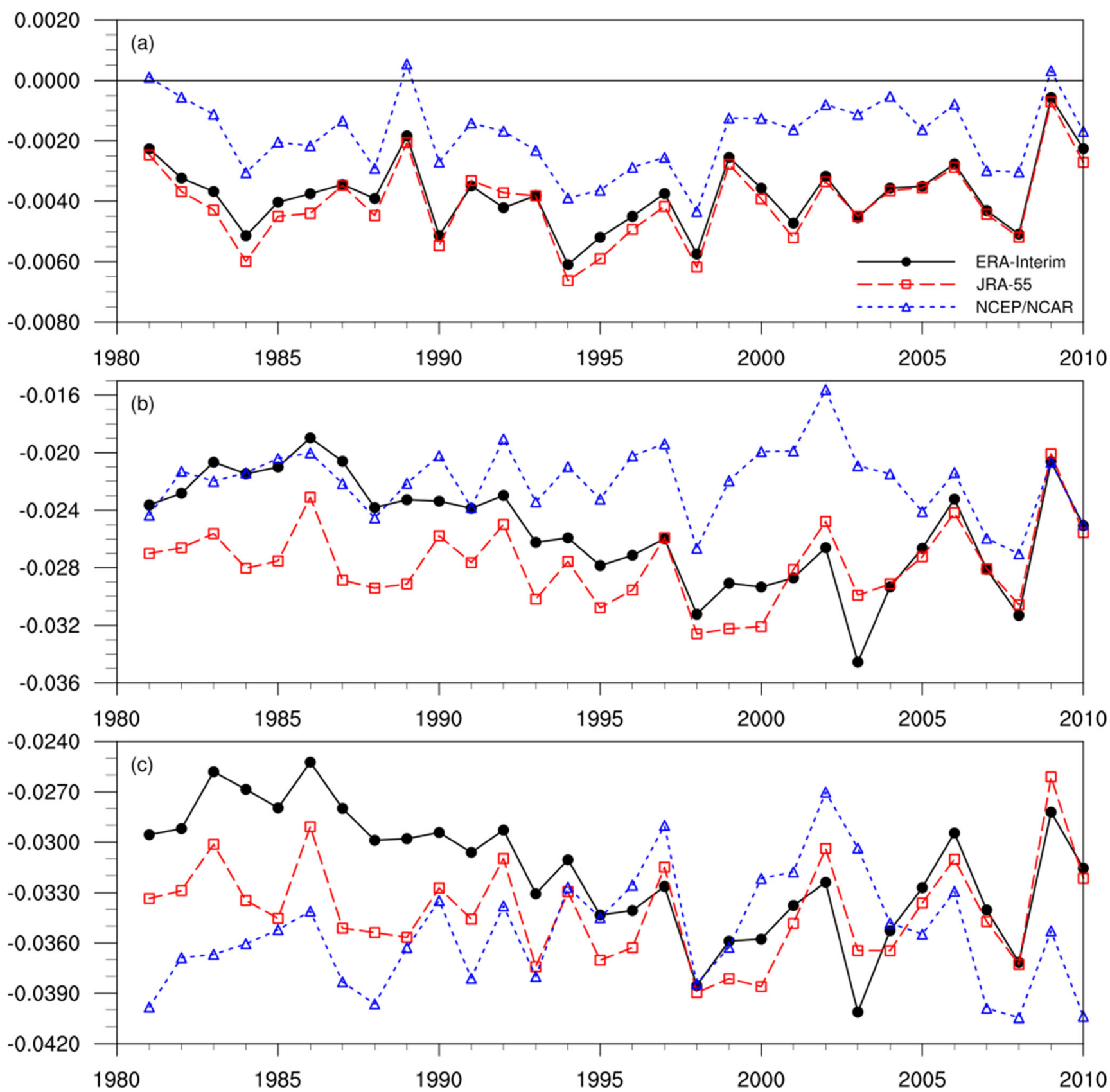

Fig. 8 The interannual trend of summer averaged air vertical velocity over the Tibetan Plateau at a $100 \mathrm{hPa}, \mathbf{b} 500 \mathrm{hPa}$, and $\mathbf{c} 600 \mathrm{hPa}$ for the period 1981-2010 based on ERA-Interim (black line), JRA-55 (red line), and NCEP/NCAR (blue line) 
Table 2 The correlation coefficient of winter (DJF) average vertical velocity of three reanalysis datasets in the Tibetan Plateau from 1981 to 2010

\begin{tabular}{llll}
\hline & r_EJ & r_EN & r_JN \\
\hline $600 \mathrm{hPa}$ & $0.39^{*}$ & $0.40^{*}$ & $0.74^{*}$ \\
$500 \mathrm{hPa}$ & $0.45^{*}$ & $0.42^{*}$ & $0.83^{*}$ \\
$100 \mathrm{hPa}$ & $0.98^{*}$ & $0.85^{*}$ & $0.83^{*}$ \\
\hline
\end{tabular}

using $90^{\circ} \mathrm{E}$ meridional January average vertical circulation profiles calculated from wind data, which support the results from ERA-Interim and JRA-55. Between $500 \mathrm{hPa}$ and $600 \mathrm{hPa}$, the vertical velocity values of ERA-Interim and NCEP/NCAR show no significant change. ERA-Interim values are in the range $0.000-0.015 \mathrm{~Pa} / \mathrm{s}$, and NCEP/NCAR values are in the range $0.0015-0.028 \mathrm{~Pa} / \mathrm{s}$. The sinking velocity in JRA-55 increases as the isobaric surface gets lower, and it ranges from $0.030 \mathrm{~Pa} / \mathrm{s}$ to $0.050 \mathrm{~Pa} / \mathrm{s}$ at $600 \mathrm{hPa}$. From the perspective of correlation, the interannual trends of JRA-55 and NCEP/NCAR are more consistent, with correlation coefficients of 0.83 and 0.74 at $500 \mathrm{hPa}$ and $600 \mathrm{hPa}$, respectively. The correlation between ERA-Interim and the other two datasets is low. The most significant differences between the ERA-Interim trend and the trends of JRA-55 and NCEP/ NCAR occurred between 2003 to 2007. During these four years, the variation in ERA-Interim values is approximately
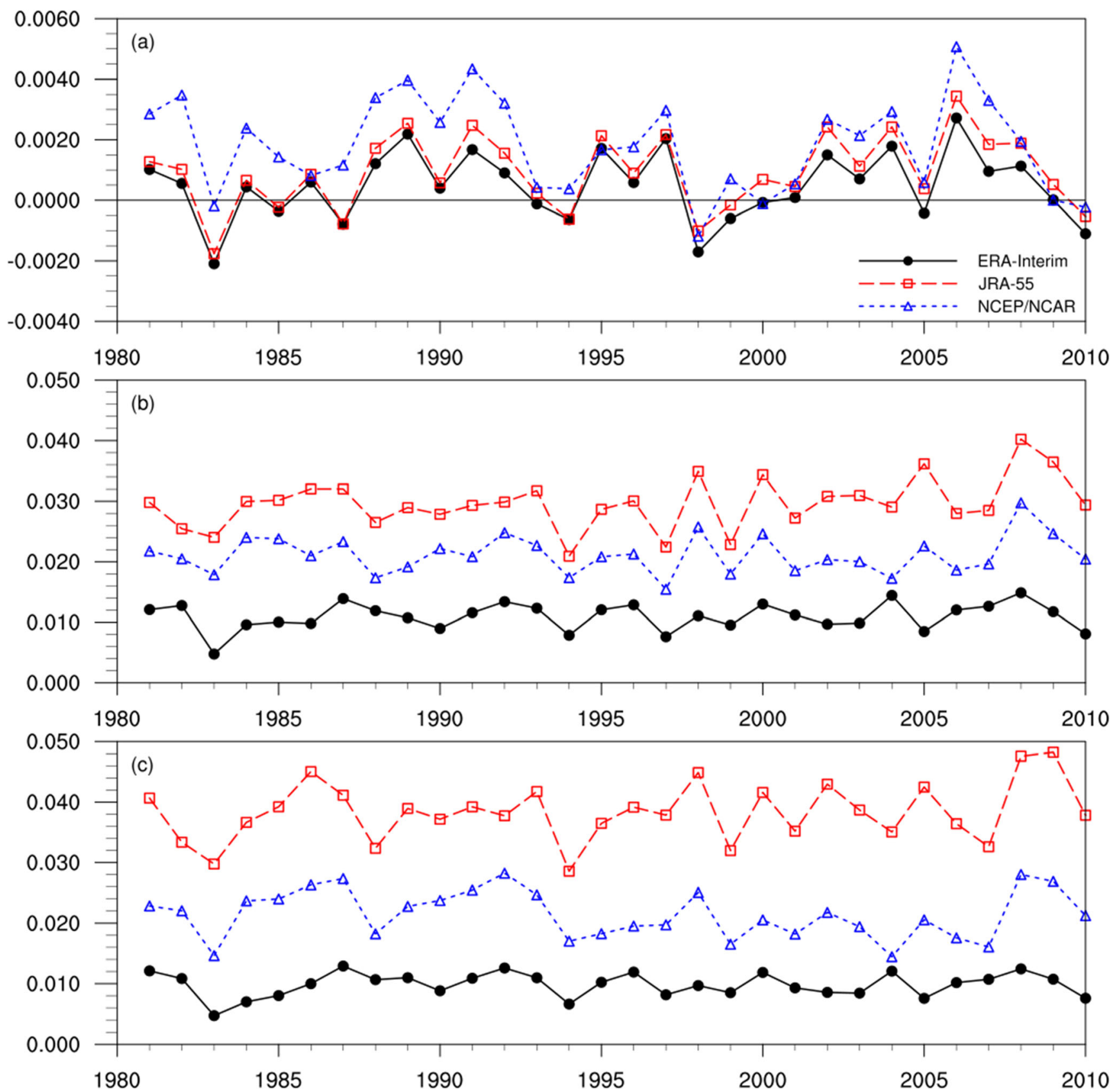

Fig. 9 As in Fig. 8 but for winter 
inverse to those of the other two datasets. In addition, the absolute values of vertical velocity in ERA-Interim are the lowest among the datasets.

In conclusion, the winter-averaged air vertical velocity over the region is highest in JRA-55, especially at $600 \mathrm{hPa}$ and its trend is consistent with that of NCEP/NCAR. Both datasets are suitable for future research on the atmosphere over the Tibetan Plateau during winter. As for the choice between JRA-55 and NCEP/NCAR, it is necessary to validate each dataset using observational data and then choose the more accurate of the two.

\section{Conclusions}

Using three widely-used reanalysis datasets (ERA-Interim, JRA-55 and NCEP/NCAR), we have used several analysis methods to compare the distribution of air vertical velocity over China at different isobaric surfaces to judge the applicability of the datasets. We then further explored the applicability of data for the Tibetan Plateau region and its vicinity. Our main conclusions are as follows.

From the perspective of climatic and seasonal averages of air vertical velocity, the positions of the ascending and sinking centers in the different tropospheric layers are basically the same in the three datasets. With regard to the magnitude and spatial distribution of the vertical motion centers, ERAInterim and JRA-55 are closer to each other than they are to NCEP/NCAR. The air vertical motion centers of ERA-Interim and JRA-55 is also significantly more detailed than that of NCEP/NCAR. Moreover, the average vertical velocity distribution at $100 \mathrm{hPa}$ over the South China Sea and the Bay of Bengal in NCEP/NCAR is completely opposite to that in ERA-Interim and JRA-55, and we therefore conclude that NCEP/NCAR is not suitable for the study of atmospheric vertical motion in the upper troposphere over this region. Both ERA-Interim and JRA-55 are more suitable for the study of atmospheric vertical motion over China and adjacent regions.

From the perspective of the distribution of atmospheric vertical motion over the Tibetan Plateau in summer, the results from JRA-55 are closer to the results of previous studies based on wind measurements. The data stability of JRA-55 is the best among the three datasets. Therefore, JRA-55 may be more suitable than ERAInterim for the study of vertical motion over the Tibetan Plateau in summer. In winter, the results from the three reanalysis datasets do not show significant differences with regard to the spatial distribution. However, the interannual variation results are more similar for JRA-55 and NCEP/NCAR. The intensity of vertical motion, whether ascending or descending, is strongest in JRA-55 at every isobaric surface considered. So even though JRA-55 is the most appropriate choice for the research over the Tibetan Plateau compared with ERA-Interim and NCEP/NCAR, it is better to combine with some observations from meteorological sites or satellites when using it.

In summary, JRA-55 is the optimal choice among the three datasets considered in this study for research into the atmospheric vertical velocity over the whole of China and for the Tibetan Plateau region in isolation. ERA-Interim performs almost as well as JRA-55, but its performance in the Tibetan Plateau is not as good as JRA-55, making it the second choice. With less details, and with features in the lower troposphere that are opposite to those in the other two datasets, NCEP/NCAR data is the last choice among the three.

Despite the clear conclusions of this work, there are some shortcomings. For example, it has only compared reanalysis data with reanalysis data, rather than using observational data as ground truth to verify the reanalysis products, which reduces the credibility of the conclusions. The reason for this is the lack of continuous observations of air vertical velocity. The radar observations only include some individual time periods for individual stations. A second shortcoming of this work is that we have performed only a qualitative comparison of the vertical velocity data; we haven't provided the criteria for quantitative evaluation and the comparison method was relatively simple. More in-depth research will be helpful in understanding the similarities and differences in vertical velocity among reanalysis datasets, and can help researchers choose the most appropriate data to use in their future research.

Acknowledgements This work was supported by the Second Tibetan Plateau Scientific Expedition and Research Program (STEP) (Grant No. 2019QZKK0103) and the National Natural Science Foundation of China (Grant No. 41775142).

Open Access This article is licensed under a Creative Commons Attribution 4.0 International License, which permits use, sharing, adaptation, distribution and reproduction in any medium or format, as long as you give appropriate credit to the original author(s) and the source, provide a link to the Creative Commons licence, and indicate if changes were made. The images or other third party material in this article are included in the article's Creative Commons licence, unless indicated otherwise in a credit line to the material. If material is not included in the article's Creative Commons licence and your intended use is not permitted by statutory regulation or exceeds the permitted use, you will need to obtain permission directly from the copyright holder. To view a copy of this licence, visit http://creativecommons.org/licenses/by/4.0/.

\section{References}

Bourke, W.: A multi-level spectral model. I. Formulation and hemispheric integrations. Monthly Weather Review. 102, 687-701 (1974). 
https://doi.org/10.1175/1520-0493(1974)102<0687:AMLSMI>2.0. $\mathrm{CO} ; 2$

China Meteorological Administration: High-altitude wind data in China: Generic. Shanghai No.4 Printing Factory, Shanghai (1972)

Dunn, L.B.: Evaluation of Vertical Motion - Past, Present, and Future. Weather and Forecasting. 6(1), 65-75 (1991). https://doi.org/10. 1175/1520-0434(1991)006<0065:Eovmpp>2.0.Co;2

ECMWF: Part III: Dynamics and Numerical Procedures: IFS documentation CY36R1. European Centre for Medium-Range Weather Forecasts (2010)

Gu, Z.: Analysis and calculation of large scale vertical motion. Acta Meteorologica Sinica. 25(3), 147-164 (1954)

He, D., Tian, H., Deng, W.: Applicability analysis of three reanalysis surface temperature data over the Tibetan Plateau. Trans Atmos Sci. 36(4), 458-465 (2013). https://doi.org/10.13878/j.cnki. dqkxxb.2013.04.009

Hu, M., You, Q., Lin, H.: Comparative analyses of geopotential height and wind field from multiple reanalysis data over the Tibetan plateau. J. Glaciol. Geocryol. 37(5), 1229-1244 (2015). https://doi.org/ 10.7522/j.isnn.1000-0240.2015.0137

$\mathrm{Hu}, \mathrm{S}$.: Three-dimensional circulation decomposition of global atmospheric motion and analysis of atmospheric vertical motion characteristics. Lanzhou University (2006)

Huang, G.: The assessment and difference of the interdecadal variations of climate change in northern part of China with the NCEP/NCAR and ERA-40 reanalysis data. Clim Environ Res. 11(3), 310-320 (2006)

Institute of Central Meteorological Bureau: Institute of Central Meteorological Bureau: Northern Hemisphere High Altitude Climate Atlas. In: Whole, vol. Book, Beijing (1972)

Kalnay, E., Kanamitsu, M., Kistler, R., Collins, W., Deaven, D., Gandin, L., Iredell, M., Saha, S., White, G., Woollen, J., Zhu, Y., Chelliah, M., Ebisuzaki, W., Higgins, W., Janowiak, J., Mo, K.C., Ropelewski, C., Wang, J., Leetmaa, A., Reynolds, R., Jenne, R., Joseph, D.: The NCEP/NCAR 40-year reanalysis project. B Am Meteorol Soc. 77(3), 437-471 (1996). https://doi.org/10.1175/ 1520-0477(1996)077<0437:Tnyrp >2.0.Co;2

Kobayashi, S., Ota, Y., Harada, Y., Ebita, A., Moriya, M., Onoda, H., Onogi, K., Kamahori, H., Kobayashi, C., Endo, H., Miyaoka, K., Takahashi, K.: The JRA-55 reanalysis: general specifications and basic characteristics. J Meteorol Soc Japan. Ser. II. 93(1), 5-48 (2015). https://doi.org/10.2151/jmsj.2015-001

Lanzhou Institute of Plateau Atmospheric Physics: Plateau Climate Atlas: Whole, vol. Book. Nanjing University, Nanjing (1979)

Li, R., Lv, S., Han, B., Gao, Y.: Preliminary comparison and analyses of air temperature at $2 \mathrm{~m}$ height between three reanalysis data-sets and observation in the east of Qinghai-Xizang plateau. Plateau Meteorol. 31(6), 1488-1502 (2012)

Tian, Y., Li, G., Liu, Y.: Comparison of the atmospheric heat sources over the Tibetan Plateau computed by three reanalysis data sets. Desert Oasis Meteorol. 11(4), 1-8 (2017). https://doi.org/10. 12057/j.issn.1002-0799.2017.04.001

Wang, B.: Comparision between NCEP and NASA Reanalysis Data in Qinghai-Tibet Plateau Area and Activities of South Asia High and its Influence on Drought and Flood Anomaly of China in Summer. (2011)

Wang, M.R., Zhou, S.W., Duan, A.M.: Trend in the atmospheric heat source over the central and eastern Tibetan plateau during recent decades: comparison of observations and reanalysis data. Chin. Sci. Bull. 57(5), 548-557 (2012). https://doi.org/10.1007/s11434$011-4838-8$

Wang, W., Gao, Y., Xu, J.: Applicability of GLDAS and climate change in the Qinghai-Xizang plateau and its surrounding arid area. Plateau Meteorol. 32(3), 635-645 (2013). https://doi.org/10.7522/j.issn. 1000-0534.2013.00054

Wei, L., Li, D.: Evaluation of NCEP/DOE surface flux data over QinghaiXizang plateau. Plateau Meteorology. 22(5), 478-487 (2003)

Wu, R., Xie, S.-P.: On equatorial Pacific surface wind changes around 1977: NCEP-NCAR reanalysis versus COADS observations. J Clim; Boston. 16(1), 167-173 (2003)

$\mathrm{Xu}, \mathrm{G} ., \mathrm{Zhang}, \mathrm{Z}$. : The effect of Qinghai-Tibet plateau on the formation of arid climate in Northwest China. Plateau Meteorol. 02, 9-16 (1983)

Xun, X., Hu, Z., Wu, X., Xue, Z., Cui, G., Yang, L., Wang, X.: Comparative analyses of three geopotential height reanalysis data in Qinghai-Xizang plateau. plateau Meteorol. 30(6), 1444-1452 (2011)

Yang, G., Wang, X., Yeh, T.: The average vertical circulations over the East-Asia and the Pacific area, (II) in winter. Scientia Atmospherica Sinica. 3(4), 299-305 (1979)

Yeh, T., Yang, G., Wang, X.: The average vertical circulations over the East-Asia and the Pacific area, (I) in summer. Scientia Atmospherica Sinica. 3(3), 1-11 (1979)

Zhao, T., Ai, L., Feng, J.: An intercomparison between NCEP reanalysis and observed data over China. Clim Environ Res. 9(2), 278-294 (2004)

Zhao, T., Fu, C.: Applicability evaluation of surface air temperature from several reanalysis datasets in China. Plateau Meteorol. 28(3), 594 606 (2009)

Publisher's Note Springer Nature remains neutral with regard to jurisdictional claims in published maps and institutional affiliations. 